\title{
Aspects of Growth Hormone (GH) Replacement in Elderly Patients with GH Deficiency: Data from KIMS
}

\author{
John P. Monson ${ }^{a}$ Peter Jönsson ${ }^{b}$ \\ aSt Bartholomew's Hospital and The Royal London, Queen Mary's School of Medicine and Dentistry,

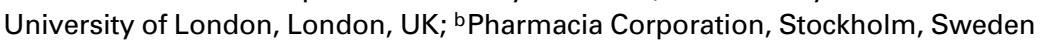

\section{Key Words}

Growth hormone - Growth hormone deficiency • Hypopituitarism - Growth hormone replacement • Elderly patients · Elderly growth hormone deficiency

\begin{abstract}
This study was designed to examine the clinical characteristics of adult-onset growth hormone deficiency (AOGHD) in patients aged over 65 years in comparison with patients aged less than 65 years. In addition, the effects of 12 months of $\mathrm{GH}$ replacement therapy on body composition, carbohydrate metabolism, blood pressure, serum lipids and quality of life were compared between patients aged over 65 years and patients under 45 years, 45-55 years and 55-65 years of age. The investigation was an observational study of patients enrolled in KIMS (Pharmacia International Metabolic Database). Baseline clinical characteristics were qualitatively similar, and scores from the Assessment of Quality of Life in GH-deficient Adults questionnaire (QoL-AGHDA) were indistinguishable between patients aged over 65 years and younger patients. Improvements in QoL-AGHDA scores were similar in all age groups during $\mathrm{GH}$ replacement therapy. Significant reductions in total and low-density lipoprotein cholesterol levels were observed in all
\end{abstract}

\section{KARGER}

Fax + 41613061234

E-Mail karger@karger.ch

www.karger.com
(C) 2003 S. Karger AG, Basel

0301-0163/03/0607-0112\$19.50/0

Accessible online at:

www. karger.com/hre groups and tended to be greater in patients aged over 65 years. Waist circumference and waist:hip ratio were not influenced by $\mathrm{GH}$ replacement therapy in women aged over 65 years, which was in contrast to the reductions observed in younger male and female patients and the decrease in waist circumference observed in men aged over 65 years. The similarities and differences in response to $\mathrm{GH}$ replacement therapy between patients aged over 65 years and those aged less than 65 years remained evident when the latter group was stratified by age. In conclusion, older patients with AO-GHD who receive $\mathrm{GH}$ replacement therapy achieve beneficial effects equivalent to those seen in younger patients in all age groups and require lower doses of $\mathrm{GH}$.

Copyright $\odot 2003$ S. Karger AG, Basel

\section{Introduction}

The clinical features of growth hormone $(\mathrm{GH})$ deficiency in hypopituitary adults and favourable responses to $\mathrm{GH}$ replacement therapy are now well recognized [17]. Normal ageing is associated with a progressive decline in spontaneous GH secretion, which appears to be, at least in part, related to an augmentation of somatostatinergic tone as acute $\mathrm{GH}$ responsiveness in elderly individu-
Prof. J.P. Monson

Department of Endocrinology, St Bartholomew's Hospital

West Smithfield

London, EC1A 7BE (UK)

Tel. +44 207601 8346, Fax +44 207601 8505, E-Mail J.P.Monson@qmul.ac.uk 
als is increased following administration of arginine [8,9]. Furthermore, it has been suggested that some clinical features of ageing are similar to those of pathological $\mathrm{GH}$ deficiency (GHD) and might be directly attributable to this physiological relative GHD [10-13]. Consequently, a number of studies have examined the effect of $\mathrm{GH}$ or $\mathrm{GH}$ releasing hormone therapy on various clinical parameters in normal elderly people [14-22]. Generally, the effects of GH replacement therapy in these studies have only been of marginal benefit. The findings have raised three important questions regarding the clinical status of older hypopituitary patients. First, is it possible to diagnose GHD in older patients with pituitary disease in comparison with age-matched controls? Second, do older patients with GHD manifest phenotypic abnormalities that are distinct from those of normal ageing? Third, do older GH-deficient patients demonstrate beneficial effects from $\mathrm{GH}$ replacement therapy? Dealing with these in turn, it has been clearly documented that GH responses to both insulin-induced hypoglycaemia and intravenous arginine are decreased in elderly hypopituitary patients compared with age-matched controls [23, 24]. Furthermore, it has been shown that total and regional fat mass are increased in elderly hypopituitary patients compared with elderly control individuals [25]. More recently, preliminary studies, including data from KIMS (Pharmacia International Metabolic Database), have demonstrated improvements in the quality of life, body composition and lipoprotein profiles in hypopituitary adults aged over 60 years when given $\mathrm{GH}$ replacement therapy in comparison with normal elderly individuals [26-28]. These improvements are qualitatively similar to those observed in younger patients, but a detailed comparison with the responses stratified by age has not previously been reported. The aim of the present study, therefore, was to compare the clinical characteristics of all patients with adult-onset GHD (AOGHD) aged over 65 years enrolled in KIMS with younger patients with AO-GHD. In addition, the effects of 12 months of GH replacement therapy on body composition, carbohydrate metabolism, blood pressure, serum lipids and quality of life were compared between patients aged over 65 years and patients aged less than 45 years, $45-55$ years, and 55-65 years.

\section{Patients and Methods}

KIMS Outcomes Research Database

KIMS is a pharmacoepidemiological survey of adult GH-deficient patients treated with GH replacement therapy. At present, more than 8,000 patients from 26 countries are enrolled in KIMS.
Following enrolment, patients are seen in local clinics at a frequency determined by the treating physician, with one visit per year being mandatory. At each visit, data are collected on specific case record forms and entered into a central database. Quality of data collection is monitored by clinical research representatives according to Good Clinical Practice Guidelines and the accuracy of data entry into the database is monitored by internal audit.

\section{Patients}

The analysis of baseline characteristics used information from 170 patients (103 men) with AO-GHD aged over 65 years commencing GH therapy at the time of enrolment into KIMS. Data were available for the effects of 12 months of GH therapy in 135 ( $83 \mathrm{men}$ ) of these patients. None of the patients had a previous history of acromegaly or Cushing's disease. The data were compared with 1,395 patients ( $711 \mathrm{men}$ ) with AO-GHD aged less than 65 years enrolled in KIMS. Patients aged less than 65 years had not received GH therapy for at least 6 months before enrolment into the study and there was no previous history of acromegaly or Cushing's disease. Patients were subdivided further into age groups of less than 45 years $(n=578)$, $45-55$ years $(n=464)$ and $55-65$ years $(n=353)$ of which 12-month treatment data were available for 476,370 and 276 patients, respectively. GH replacement therapy was initiated at a maximum dose of $0.125 \mathrm{IU} / \mathrm{kg} /$ week $(0.042 \mathrm{mg} / \mathrm{kg} /$ week $)$ with a subsequent increase to a maximum of $0.25 \mathrm{IU} / \mathrm{kg} /$ week $(0.083 \mathrm{mg} / \mathrm{kg} /$ week $)$ based on individual responses. Within this maximum dosing guideline, the majority of patients were managed by dose titration against clinical response and serum insulin-like growth factor I (IGF-I) measurement. The aetiology and severity of GHD (peak GH and IGF-I standard deviation score [SDS]) in patients aged over and less than 65 years are provided in table 1 .

\section{Methods}

Serum concentrations of IGF-I were measured by an HCl-extraction radioimmunoassay. Intra- and interassay coefficients of variation were less than $9 \%$ in the concentration range $125-1,046 \mu \mathrm{g} / \mathrm{l}$.

Serum levels of total cholesterol were measured as described by Lie et al. [29], high-density lipoprotein (HDL) cholesterol was measured according to the method of Lopez-Virella et al. [30], and triglyceride levels were estimated by a hydrogen peroxide generation colorimetric method [31]. Serum low-density lipoprotein (LDL) cholesterol concentrations were calculated according to the Friedewald formula [32]. All serum IGF-I and lipid analyses were conducted in a single laboratory.

Blood pressure was measured supine after $5 \mathrm{~min}$ of rest. Waist and hip circumference measurements were conducted according to the KIMS guideline circulated to all participating clinics. Quality of life was assessed by the Assessment of Quality of Life in GH-deficient Adults questionnaire (QoL-AGHDA), a disease-sensitive, needs-based quality of life questionnaire which was developed specifically for adult GHD [33]. It has shown excellent reliability and crosscultural comparability and has proven to be a sensitive means of monitoring changes in quality of life during long-term GH replacement therapy [7]. A higher QoL-AGHDA score, to a maximum of 25, indicates a poorer quality of life.

\section{Statistical Analysis}

Data analyses were performed using SAS (the Statistical Analysis System developed by the SAS Institute, USA). The significance of the effects of GH therapy was determined within each group by paired 
Table 1. Baseline clinical characteristics of male and female patients aged over and less than 65 years

\begin{tabular}{|c|c|c|c|}
\hline & Age $>65$ years & Age $<65$ years & $\mathrm{p}$ \\
\hline Patients, $\mathrm{n}$ & 170 & 1,395 & \\
\hline Age, years & $69.1(65.6-74.1)$ & $47.9(31.4-60.3)$ & $<0.0001$ \\
\hline Males, $\%$ & 61.8 & 51.0 & 0.008 \\
\hline Females, $\%$ & 38.2 & 49.0 & 0.008 \\
\hline Pituitary adenoma, $\%$ & 77.1 & 57.9 & $<0.001$ \\
\hline Craniopharyngiomas, $\%$ & 4.7 & 11.7 & $<0.01$ \\
\hline Other pituitary/hypothalamic tumours, $\%$ & 3.5 & 4.0 & ns \\
\hline Cranial tumours, $\%$ & 0.0 & 2.7 & na \\
\hline Treated malignancies, $\%$ & 0.0 & 0.4 & na \\
\hline Other causes, $\%$ & 8.2 & 15.1 & $<0.05$ \\
\hline Idiopathic, $\%$ & 6.5 & 8.2 & ns \\
\hline Duration of pituitary disease, $\%$ & $5.4(1.3-23.3)$ & $4.5(0.96-18.9)$ & 0.051 \\
\hline Number of additional deficiencies, $\%$ & & & 0.38 \\
\hline 0 & 5.3 & 10.0 & $<0.05$ \\
\hline 1 & 12.4 & 13.1 & ns \\
\hline 2 & 22.4 & 15.7 & $<0.05$ \\
\hline 3 & 48.8 & 40.4 & $<0.05$ \\
\hline 4 & 11.2 & 20.9 & $<0.05$ \\
\hline \multirow[t]{2}{*}{ Peak GH on stimulation test, $\mathrm{ng} / \mathrm{ml}$} & Male: $0.33(0.07-2.40)$ & Male: $0.42(0.10-2.20)$ & 0.15 \\
\hline & Female: $0.23(0.03-1.90)$ & Female: $0.60(0.10-2.70)$ & $<0.0001$ \\
\hline \multirow[t]{2}{*}{ IGF-I SDS } & $\begin{array}{l}\text { Male: }-1.60 \\
(-3.19 \text { to }+0.28)\end{array}$ & $\begin{array}{l}\text { Male: }-1.76 \\
(-4.36 \text { to }+0.27)\end{array}$ & 0.67 \\
\hline & $\begin{array}{l}\text { Female: }-1.78 \\
(-3.81 \text { to } 0.06)\end{array}$ & $\begin{array}{l}\text { Female: }-2.37 \\
(-4.84 \text { to }-0.22)\end{array}$ & 0.04 \\
\hline
\end{tabular}

ns $=$ Not significant $;$ na $=$ not applicable.

Data are given as median (10th-90th percentiles) or percentage of patients in the age group.

$t$ tests, and between the groups by unpaired $t$ tests if the data were normally distributed, and using Wilcoxon rank sum tests if they were not. Comparisons of proportions of various aetiologies and numbers of additional hormone deficiencies were performed using the Fischer exact and $\chi^{2}$ tests. Significance was accepted at $p$ values of $<0.05$.

\section{Results}

\section{Baseline Characteristics}

Details of aetiology, estimated duration of hypopituitarism, the number of additional pituitary hormone deficiencies, peak GH response to provocative stimulation, and baseline IGF-I SDS are provided in table 1. Adenoma was more common in patients aged over 65 years and craniopharyngioma was more common in younger patients. The diagnosis of GHD was made by insulin tolerance test in 55 and $51 \%$, by arginine testing in 14 and $14 \%$, by glucagon testing in 5 and $9 \%$, and by other methods in 26 and $26 \%$ of patients aged over and less than 65 years, respectively. Mean peak serum GH level in response to provocative testing was significantly lower in female patients aged over 65 years compared with younger patients $(\mathrm{p}<0.001)$, but mean peak serum GH concentrations in male patients older and younger than 65 years of age were similar. Peak serum GH levels were less than $3 \mathrm{ng} / \mathrm{ml}$ in 93 and $94 \%$ of patients aged less than and over 65 years, respectively. Serum IGF-I SDS was significantly higher in female patients aged over 65 years compared with younger patients, but the values in male patients were similar between the age groups. The duration of pituitary disease tended to be longer in patients aged over 65 years $(\mathrm{p}=0.051)$.

Details of baseline waist:hip ratio, lipoprotein profiles, glycated haemoglobin (HbA1c), systolic and diastolic blood pressure, prevalence of hypertension and diabetes mellitus, and QoL-AGHDA scores are provided in tables 2 and 3. Prevalence of diagnosed hypertension was significantly higher in women aged over 65 years compared with younger women $(\mathrm{p}<0.0001)$, but there was no significant difference between older and younger men. Similarly, the prevalence of diabetes mellitus was significantly higher in older women compared with the younger 
Table 2. Baseline body mass index (BMI), waist:hip ratio, lipoprotein profiles, glycated haemoglobin (HbAlc), systolic and diastolic blood pressure (BP), prevalence of hypertension, prevalence of diabetes mellitus and QoL-AGHDA score in male patients aged over and less than 65 years
Table 3. Baseline body mass index (BMI), waist:hip ratio, lipoprotein profiles, glycated haemoglobin (HbA1c), systolic and diastolic blood pressure (BP), prevalence of hypertension, prevalence of diabetes mellitus and QoL-AGHDA score in female patients aged over and less than 65 years

\begin{tabular}{lccc}
\hline & Age $>65$ years & Age $<65$ years & $\mathrm{p}$ \\
\hline BMI, kg/m ${ }^{2}$ & $28.1 \pm 4.2$ & $28.9 \pm 4.9$ & 0.18 \\
Waist:hip ratio & $0.97 \pm 0.06$ & $0.97 \pm 0.09$ & 0.35 \\
Total cholesterol, m $M$ & $5.79 \pm 1.07$ & $5.94 \pm 1.25$ & 0.71 \\
LDL-cholesterol, $M M$ & $3.76 \pm 0.93$ & $3.85 \pm 1.17$ & 0.95 \\
HDL-cholesterol, mM & $1.20 \pm 0.36$ & $1.15 \pm 0.33$ & 0.28 \\
Triglycerides, $M$ & $1.90 \pm 0.92$ & $2.23 \pm 1.41$ & 0.17 \\
Systolic BP, mm Hg & $141.3 \pm 18.9$ & $129.6 \pm 17.5$ & $<0.0001$ \\
Diastolic BP, mm Hg & $83.3 \pm 10.4$ & $80.9 \pm 11.2$ & $<0.02$ \\
HbA1c, \% & $5.34 \pm 0.76$ & $5.07 \pm 0.85$ & $<0.003$ \\
Prevalence of hypertension, \% & 24.0 & 16.6 & 0.063 \\
Prevalence of diabetes mellitus, \% & 3.9 & 4.2 & 0.86 \\
QoL-AGHDA score & $7.9 \pm 6.4$ & $9.0 \pm 6.6$ & 0.19 \\
\hline
\end{tabular}

$\mathrm{HDL}=$ High-density lipoprotein; $\mathrm{LDL}=$ low-density lipoprotein.

Data are shown as mean \pm SD.

\begin{tabular}{lccc}
\hline & Age $>65$ years & Age $<65$ years & $\mathrm{p}$ \\
\hline BMI, kg/m ${ }^{2}$ & $29.9 \pm 5.5$ & $28.2 \pm 6.0$ & $<0.02$ \\
Waist:hip ratio & $0.90 \pm 0.07$ & $0.86 \pm 0.07$ & $<0.01$ \\
Total cholesterol, $\mathrm{m} M$ & $6.70 \pm 1.52$ & $6.12 \pm 1.27$ & $<0.01$ \\
LDL-cholesterol, $\mathrm{m} M$ & $4.42 \pm 1.41$ & $3.85 \pm 1.08$ & $<0.02$ \\
HDL-cholesterol, $\mathrm{m} M$ & $1.24 \pm 0.33$ & $1.39 \pm 0.38$ & $<0.02$ \\
Triglycerides, $M$ & $2.27 \pm 1.09$ & $2.05 \pm 1.96$ & $<0.02$ \\
Systolic BP, mm Hg & $142.4 \pm 20.7$ & $125.7 \pm 17.9$ & $<0.0001$ \\
Diastolic BP, mm Hg & $81.0 \pm 9.7$ & $79.4 \pm 10.5$ & 0.18 \\
HbAlc, \% & $5.58 \pm 0.99$ & $5.12 \pm 0.90$ & $<0.002$ \\
Prevalence of hypertension, \% & 43.1 & 13.6 & $<0.0001$ \\
Prevalence of diabetes mellitus, \% & 12.3 & 3.8 & $<0.002$ \\
QoL-AGHDA score & $10.9 \pm 6.1$ & $11.5 \pm 6.8$ & 0.47 \\
\hline
\end{tabular}

HDL $=$ High-density lipoprotein; LDL = low-density lipoprotein.

Data are shown as mean \pm SD. female patients $(\mathrm{p}<0.002)$ with no significant difference between older and younger men. Older female patients demonstrated an increased body mass index and waist:hip ratio compared with the younger female patients. Mean levels of $\mathrm{HbAlc}$ were significantly higher in patients aged over 65 years compared with younger patients. Total and LDL-cholesterol were increased, and HDL-cholesterol was decreased in female patients aged over 65 years compared with younger women, but these differences were not evident in the male patients. As expected, systolic blood pressure was significantly higher in older male and female patients, but diastolic blood pressure was higher in the older male patients only. QoL-
AGHDA scores were higher in the female patients than in the male patients, but were similar between the age groups.

\section{Response to GH Replacement Therapy}

Maintenance doses of GH at 12 months in the various age groups are shown in figure 1. The dose of $\mathrm{GH}$ was significantly lower in male and female patients aged over 65 years compared with the younger age categories, and the differential was greater in women (fig. 1).

Serum IGF-I SD scores are shown in figure 2. Mean IGF-I SDS was higher in female patients aged over 65 years than in younger female patients; in male patients, 
Fig. 1. The dose of $\mathrm{GH}$ administered to patients in different age groups after 1 year of GH replacement therapy. Data are shown as mean, median and 10th-90th percentiles.
Fig. 2. IGF SDS in patients in different age groups after 1 year of GH replacement therapy. Data are shown as mean, median and 10th-90th percentiles.
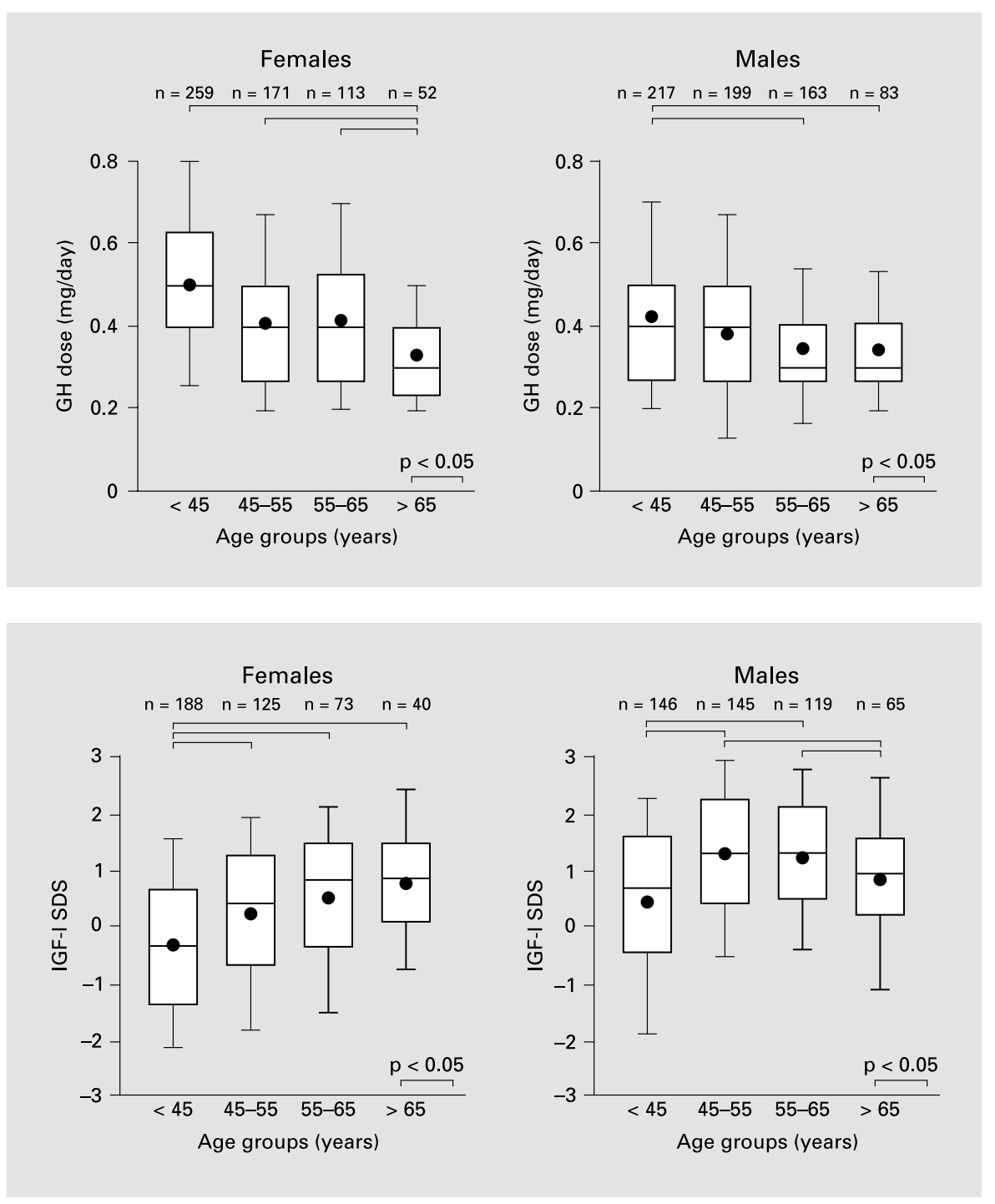

serum IGF-I SDS was higher in male patients aged 45-65 years compared with patients aged less than 45 years and over 65 years (fig. 2).

\section{Waist Circumference}

Waist circumference decreased in all age groups in both sexes $(p<0.001)$, but there were no differences in the degree of change in the waist circumference between the age groups (fig. 3).

\section{Fasting Plasma Glucose and HbAlc}

Mean fasting plasma glucose levels increased slightly in patients aged less than 65 years, but no significant increment was evident in older male and female patients (fig. 4). A parallel increment in HbAlc concentrations was seen in patients aged less than 65 years (fig. 4).

\section{Systolic and Diastolic Blood Pressure}

There was no significant change in systolic blood pressure in either sex across the age groups (fig. 5). In contrast, diastolic blood pressure fell significantly in women aged younger than 45 years $(p<0.003)$ and in men aged over 65 years $(p<0.05)$ compared with baseline data (fig. 6$)$. Furthermore, the reduction in diastolic blood pressure was significantly greater in male patients aged over 65 years than in males aged less than 55 years and in females aged less than 55 years compared with women over 65 years (fig. 6). 
Fig. 3. Change in waist circumference in patients in different age groups after 1 year of GH replacement therapy. Data are shown as mean, median and 10th-90th percentiles.

Fig. 4. Change in indices of glucose metabolism in patients aged $<65$ or $>65$ years after 1 year of GH replacement therapy. Data are shown as mean, median and 10th-90th percentiles. ${ }^{*} \mathrm{p}<0.0001$ vs. baseline.

Fig. 5. Change in systolic blood pressure (BP) in patients in different age groups after 1 year of GH replacement therapy. Data are shown as mean, median and 10th-90th percentiles.
Females
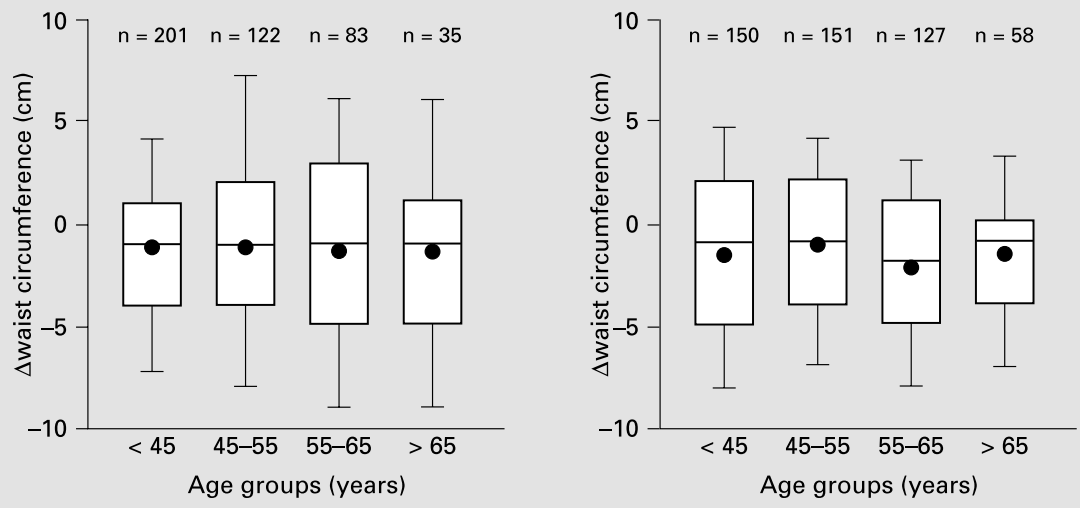
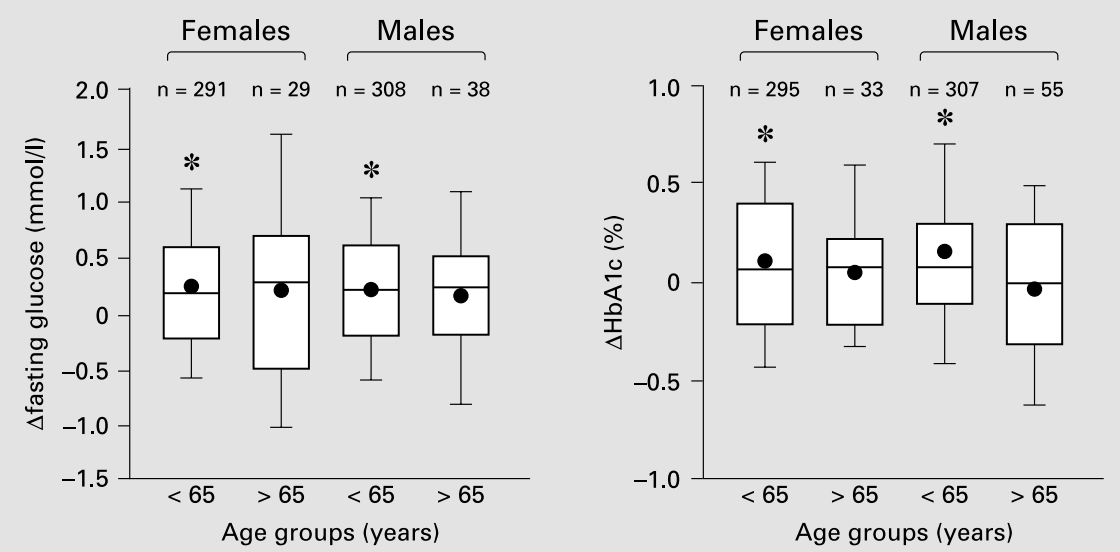
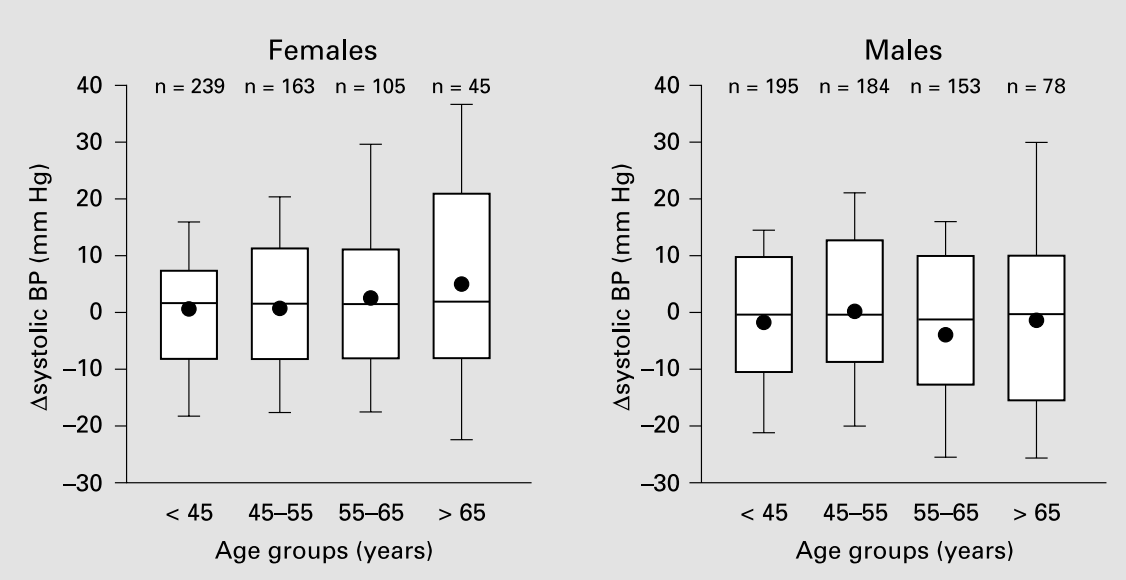
Fig. 6. Change in diastolic blood pressure (BP) in patients in different age groups after 1 year of GH replacement therapy. Data are shown as mean, median and 10th-90th percentiles.

Fig. 7. Change in LDL-cholesterol in patients in different age groups after 1 year of GH replacement therapy. Data are shown as mean, median and 10th-90th percentiles. $\mathrm{p}<0.002$ for all groups vs. baseline.

Fig. 8. Change in QoL-AGHDA scores in patients in different age groups after 1 year of GH replacement therapy. Data are shown as mean, median and 10th-90th percentiles.
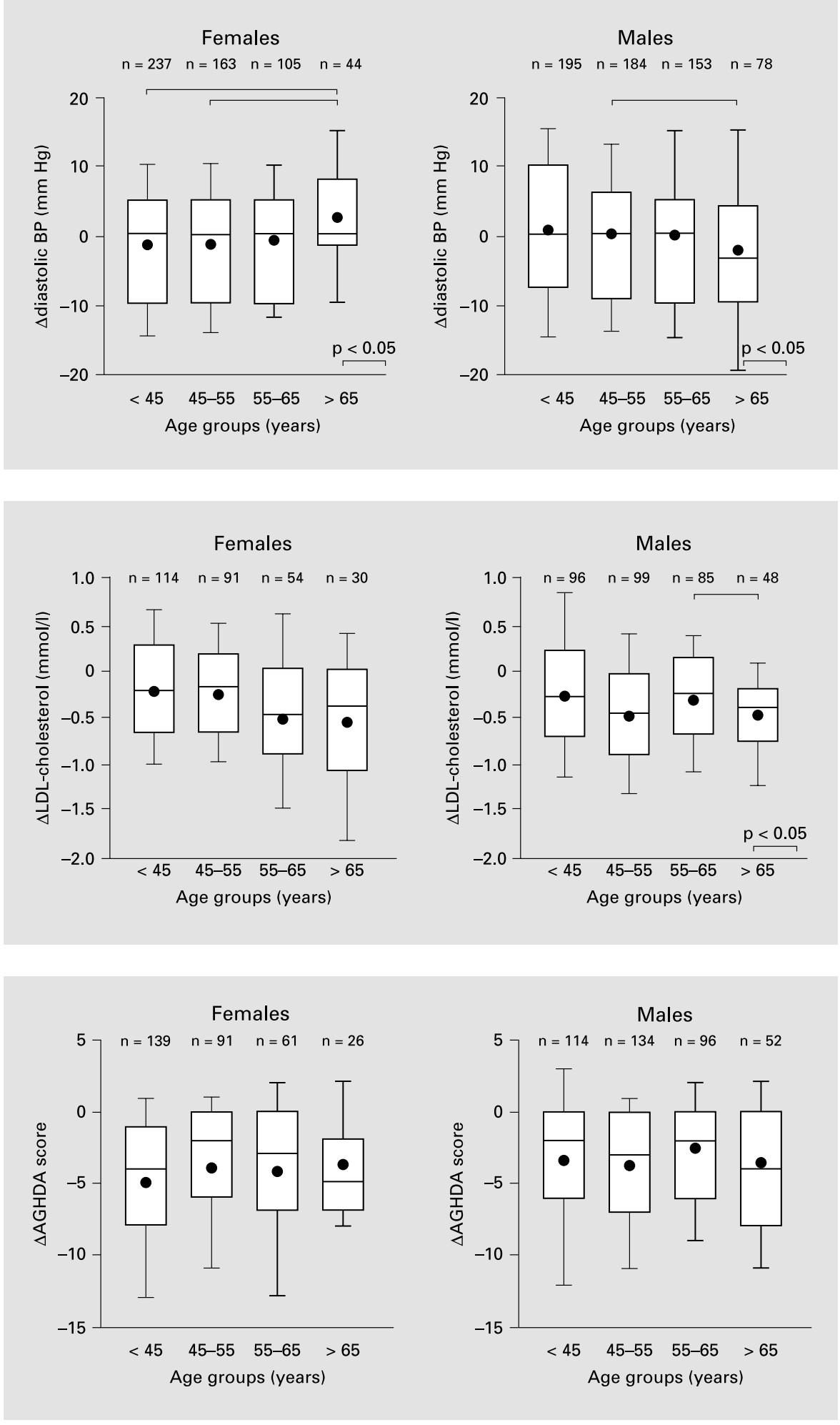


\section{Serum Lipoproteins}

Serum total and LDL-cholesterol levels decreased during the 12 months of GH replacement therapy in both male and female patients in all age groups $(p<0.002)$. The decrease in LDL-cholesterol was significantly greater in men aged over 65 years compared with younger male patients, whereas in females, there were no significant changes across the age groups (fig. 7). There were no significant changes in levels of triglycerides or HDL-cholesterol in any group.

Quality of Life

QoL-AGHDA scores improved significantly from baseline (fig. 8) for both sexes in all age groups (females aged over 65 years, $\mathrm{p}<0.001$; females aged less than 65 years, $p<0.0001$; males aged over 65 years and less than 65 years, $\mathrm{p}<0.0001)$. However, there were no significant differences between the age groups for either sex (fig. 8).

\section{Discussion}

The results of this analysis of KIMS data confirm our previous publication which examined the baseline characteristics and the response to 6 months of GH replacement therapy in elderly patients [27], and are concordant with the findings of previous single-centre studies [26, 28]. This study extends these findings by expanding the number of patients aged over 65 years and by stratifying the younger patients by age group as well as examining the response to $\mathrm{GH}$ replacement therapy over a 12-month period. Baseline clinical characteristics were qualitatively similar between the age groups and QoL-AGHDA scores in particular demonstrated a similar degree of impairment. However, older females, when compared with males, demonstrated a greater relative degree of adverse change in cardiovascular risk factors than younger patients of the same sex. All subgroups of patients had an equivalent degree of severe GHD on dynamic testing, as would be expected given the high prevalence of structural pituitary disease and severity of hypopituitarism. Although normal ageing is associated with a decline in spontaneous GH secretion, it is well established that it is possible to diagnose GHD by dynamic testing in older patients using similar criteria to those used in younger patients $[23,24]$.

The data for the dose of $\mathrm{GH}$ used and maintenance IGF-I concentration SDS are consistent with a dose-titration approach to $\mathrm{GH}$ replacement therapy. Favourable changes in waist circumference occurred in all groups and were of similar magnitude. The latter finding is in agreement with the previous demonstration of abnormal body fat and distribution in older hypopituitary adults compared with age-matched controls [25]. Furthermore, reductions in serum LDL-cholesterol levels were evident in all age groups, with the largest reduction in older male patients. These responses to GH therapy are more impressive than in our original report and are probably a reflection of the increased numbers of patients studied and, possibly, the longer duration of therapy [27]. We have again demonstrated that older patients experience a similar improvement in quality of life during GH replacement therapy and have extended this observation by confirming similar benefits gained in all stratified age groups of patients aged under 65 years.

$\mathrm{GH}$ replacement therapy is now widely used in GHdeficient adults, the majority of whom are middle aged at the start of therapy. This study provides unequivocal evidence that older GH-deficient adults obtain similar benefits to those observed in younger patients and argues for the use of GH therapy across the entire adult age range in patients with severe GHD. By inference, it is clear that the withdrawal of GH therapy in the ageing GH-deficient adult on the basis of an erroneous comparison with agerelated physiological reduction in $\mathrm{GH}$ secretion in health is inappropriate.

\section{Acknowledgements}

We are grateful to our colleagues on the KIMS Strategic Scientific Committee and International Board and to the KIMS Investigators for their major contributions. 


\section{References}

1 Jorgensen JOL, Pedersen SA, Thuesen L, Jorgensen J, Ingemann-Hansen T, Skakkabaek N, Christiansen JS: Beneficial effects of growth hormone treatment in GH-deficient adults. Lancet 1989; I:1221-1225.

2 Salomon F, Cuneo RC, Hesp R, Sönksen P. The effects of treatment with recombinant human growth hormone on body composition and metabolism in patients with growth hormone deficiency. N Engl J Med 1989;321: 1979-1803.

3 Binnerts A, Swart GR, Wilson JH, Hoogerbrugge N, Pols HA, Birkenhager JC, Lamberts SJW: The effect of growth hormone administration in growth hormone deficient adults on bone, protein, carbohydrate and lipid homeostasis, as well as on body composition. Clin Endocrinol (Oxf) 1992;37:79-87.

4 Whitehead HM, Boreham C, McIlwrath EM, Sheridan B, Kennedy L, Atkinson AB, Hadden DR: Growth hormone treatment of adults with growth hormone deficiency: results of a 13 month placebo-controlled cross-over study. Clin Endocrinol (Oxf) 1992:36:45-52.

5 Bengtsson B-Å, Eden S, Lonn L, Kvist H, Stokland A, Lindstedt G, Bosaeus I, Tolli J, Sjostrom L, Isaksson O: Treatment of adults with growth hormone deficiency with recombinant human growth hormone. J Clin Endocrinol Metab 1993;76:309-317.

6 Weaver JU, Monson JP, Noonan K, John WG, Edwards A, Evans KA, Cunningham JC: The effect of low dose recombinant growth hormone replacement on regional fat distribution, insulin sensitivity and cardiovascular risk factors in hypopituitary adults. J Clin Endocrinol Metab 1995;80:153-159.

7 Abs R, Bengtsson B-A., Hernberg-Ståhl E, Monson JP, Tauber J-P, Wilton P, Wüster C: GH replacement in 1,034 growth hormone deficient adults: demographic and clinical characteristics, dosing and safety. Clin Endocrino (Oxf) 1999;50:703-714

8 Arvat E, Gianotti L, Grottoli S, Imbimbo BP, Lenaerts V, Deghenghi R, Cammani F, Ghigo E: Arginine and growth hormone-releasing hormone restore the blunted growth hormonereleasing activity of hexarelin in elderly subjects. J Clin Endocrinol Metab 1994;79:14401443

9 Ghigo E, Arvat E, Rizzi G, Bellone J, Nicolosi M, Boffano GM, Mucci M, Boghen MF, Cammani F: Arginine enhances the growth hormone-releasing activity of a synthetic hexapeptide (GHRP-6) in elderly but not in young subjects after oral administration. J Endocrinol Invest 1994;17:157-162.

10 Rudman D, Kutner MH, Rogers CM, Lubin MF, Fleming GA, Bain RP: Impaired growth hormone secretion in the adult population: relation to age and adiposity. J Clin Invest 1981; 67:1361-1369.
11 Iranmanesh A, Lizarralde G, Veldhuis JD: Age and relative obesity are specific negative determinants of the frequency and amplitude of growth hormone $(\mathrm{GH})$ secretory bursts and the half-life of endogenous $\mathrm{GH}$ in healthy men. J Clin Endocrinol Metab 1991;73:1081-1088.

12 Corpas E, Harman SM, Blackman MR: Human growth hormone and human aging. Endocr Rev 1993;14:20-39.

13 Vahl N, Jorgensen JO, Jurik AG, Christiansen JS: Abdominal adiposity and physical fitness are major determinants of the age associated decline in stimulated $\mathrm{GH}$ secretion in healthy adults. J Clin Endocrinol Metab 1996;81: 2209-2215.

14 Binnerts A, Wilson JHP, Lamberts SJW: The effects of human growth hormone administration in elderly adults with recent weight loss. J Clin Endocrinol Metab 1988;67:1312-1316.

15 Rudman D, Feller AG, Nagraj HS, Gergans GA, Lalitha PY, Goldberg AF, Schlenker RA, Cohn L, Rudman IW, Mattson DE: Effects of human growth hormone in men over 60 years old. N Engl J Med 1990;323:1-6.

16 Holloway L, Butterfield G, Hintz R, Gesundheit N, Marcus R: Effects of recombinant human growth hormone on metabolic indices, body composition, and bone turnover in healthy elderly women. J Clin Endocrinol Metab 1994;79:470-479.

17 Taafe DR, Pruitt L, Reim J, Hintz R, Butterfield G, Hoffman AR, Marcus R: Effect of recombinant human growth hormone on the muscle strength response to resistance exercise in elderly men. J Clin Endocrinol Metab 1994; 79:1361-1366.

18 Papadakis MA, Grady D, Black D, Tierney MJ, Gooding GA, Schambelan M, Grunfeld C: Growth hormone replacement in healthy older men improves body composition but not functional ability. Ann Intern Med 1996;124:708716

19 Taafe DR, Jin IU, Vu TH, Hoffman AR, Marcus R: Lack of effect of recombinant human growth hormone $(\mathrm{GH})$ on muscle morphology and $\mathrm{GH}$-insulin-like growth factor expression in resistance trained elderly men. J Clin Endocrinol Metab 1996;81:421-425.

20 Welle S, Thornton C, Statt M, McHenry B: Growth hormone increases muscle mass and strength but does not rejuvenate neurofibrillar protein synthesis in healthy subjects over 60 years old. J Clin Endocrinol Metab 1996;81: 3239-3243.

21 Corpas E, Harman SM, Pineyro MA, Robertson R, Blackman MR: Growth hormone (GH)releasing hormone (1-29) twice daily reverses the decreased $\mathrm{GH}$ and insulin-like growth factor-I levels in old men. J Clin Endocrinol Metab 1992;75:530-535.
22 Vittone J, Blackman MR, Busby-Whitehead J, Tsiao C, Stewart KJ, Tobin J, Stevens T, Bellantoni MF, Rogers MA, Baumann G, Roth J, Harman SM, Spencer RG: Effects of single nightly injections of growth hormone-releasing hormone (GHRH 1-29) in healthy elderly men. Metabolism 1997;46:1-9.

23 Hoffman DM, O’Sullivan AJ, Baxter RC, Ho KKY: Diagnosis of growth hormone deficiency in adults. Lancet 1994;343:1064-1068.

24 Toogood AA, O’Neill PA, Shalet SM: Beyond the somatopause: growth hormone deficiency in adults over the age of 60 years. J Clin Endocrinol Metab 1996;81:460-465.

25 Toogood AA, Adams JE, O’Neill PA, Shalet SM: Body composition in growth hormone deficient adults over the age of 60 years. Clin Endocrinol (Oxf) 1996;45:399-405.

26 Toogood AA, Shalet SM: Growth hormone replacement therapy in the elderly with hypothalamic-pituitary disease: a dose-finding study. J Clin Endocrinol Metab 1999;84:131-136.

27 Monson JP, Abs R, Bengtsson B-A, Bennmarker H, Feldt-Rasmussen U, Hernberg-Ståhl E, Thorén M, Westberg B, Wilton $\mathrm{P}$, Wüster C: Growth hormone deficiency and replacement in elderly hypopituitary patients. Clin Endocrinol (Oxf) 2000;53:281-289.

28 Fernholm R, Bramnert M, Hägg E, Hilding A, Baylink DJ, Mohan S, Thorén M: Growth hormone replacement therapy improves body composition and increases bone metabolism in elderly patients with pituitary disease. J Clin Endocrinol Metab 2000;85:4104-4112.

29 Lie RF, Schmidt JM, Pierre KJ, Gochman N Cholesterol oxidase based determination by continuous-flow analysis of total and free cholesterol in serum. Clin Chem 1976;22:16271630.

30 Lopez-Virella MF, Stone P, Ellis S, Colvell JA Cholesterol determination in high density lipoproteins separated by three different methods. Clin Chem 1977:23:882-884.

31 Fossati P, Prencipe L: Serum triglycerides determined colorimetrically with an enzyme that produces hydrogen peroxide. Clin Chem 1982; 28:2077-2080.

32 Friedewald WT, Levy RI, Fredrickson DS: Estimation of the concentration of low density lipoprotein cholesterol in plasma, without use of the preparative ultracentrifuge. Clin Chem 1972;18:439-502.

33 McKenna SP, Doward LC: What is the impact of $\mathrm{GH}$ deficiency and $\mathrm{GH}$ replacement on quality of life in childhood-onset and adultonset GH deficiency; in Monson JP (ed): Challenges in Growth Hormone Therapy. Oxford, Blackwell Science, 1999, pp 160-176. 